\title{
Hybrid Charging System Management with Automatic Switching Method
}

\author{
Abdillah Fashiha Ilman \\ Department of Industrial Electrical \\ Engineering \\ Politeknik Negeri Madura \\ Sampang, Indonesia \\ abdifashiha@gmail.com
}

\author{
Fitrah Maharani Humaira \\ Department of Industrial Electrical \\ Engineering \\ Politeknik Negeri Madura \\ Sampang, Indonesia \\ humaira@poltera.ac.id \\ Imam Mawardi \\ Department of Industrial Electrical \\ Engineering \\ Politeknik Negeri Madura \\ Sampang, Indonesia \\ imam11mawardi@gmail.com
}

\author{
Dzulkiflih \\ Department of Physic \\ Universitas Negeri Surabaya \\ Surabaya, Indonesia \\ dzulkiflih@unesa.ac
}

\begin{abstract}
Hybrid energy generation is a renewable energy power plant with more efficiency and advantages than a stand-alone generator. Using 2 generators for battery storage can speed up the charging of energy to the battery but in the battery charging system, there is still wasted energy and an uncontrolled Charging and Discharging system on the battery resulting in a short battery life. Therefore, we need a tool to control the Charging and Discharging performance of the battery in order to optimize battery charging thereby extending battery life.
\end{abstract}

Automatic Switching System is an innovation of Charging and Discharging activity management so that it does not occur simultaneously on the battery, this process is carried out by a microcontroller. The use of $2 \mathrm{DC}$ power sources as a charging source helps speed up battery charging for $\mathbf{3 0}$ minutes faster than 1 source. Through several modes provided, this tool can select sources and batteries that can be used as a condition for Charging and Discharging.

Keywords-automatic switching, hybrid, management system

\section{INTRODUCTION}

Electrical energy is one of the most important aspects in human life. The development of electrical energy now leads to renewable energy such as solar energy, geothermal energy, water energy, wind energy, biomass energy, ocean wave energy and tidal energy. The development of renewable electricity generation comes along with the advancement of today's power plan technology. This is increasingly supported by the issue of global warming which affects the development of technology to be more environmentally friendly. At present the use of renewable energy as a producer of electrical energy is not a stranger to the public.

Solar power generation is one type of electric energy generation that uses photovoltaic cell panels as a generator. Electricity generated from ordinary Solar Cells has little power, therefore several Solar Cells are arranged in series to produce the desired power, one of the renewable energy sources that is also being looked at is wind power [1]. Lately, the use of windmills as power plants has begun to be used, especially in coastal areas that are considered to have abundant sources of wind. Wind power plants utilize windmills to capture the moving wind energy. The size, angle, and characteristics of the wheel will affect the electrical power to be generated. The spinning wheel will rotate the turbine and generator so as to produce electrical energy. The power generated depends greatly on the characteristics of the generator used and the wind speed when the windmill spins. With the development of the times, the discovery of windmills that have high efficiency is increasingly promising. Vertical shaft windmills are windmill innovations for average power wind speeds that have low wind speeds up to $1.5 \mathrm{~m} / \mathrm{s}$.

In the power plan system, there is the term Hybrid Power Plant. A hybrid power plant is an amalgamation of two or more power sub-systems which are connected to each other to form a large power generation system [2]. Examples of uses using hybrid power plants are in Pantai Baru, Ngetak, Poncosari, Srandakan, Bantul Regency, Yogyakarta which combines two renewable energy power plants namely Solar Cell and windmills. Merging these two renewable plants creates a Hybrid system that works to support one another. The necessary installation can also be used together, this is what makes the cost of developing hybrid power plants cheaper when compared to other types of independent power plants.

From the problems outlined above, a tool that is able to optimize the performance and capacity of electric energy storage batteries is created. This tool is focused on the management of electrical energy generated by the generator with the Automatic Switching method. Automatic Switching is a system used to maximize the capacity of electric energy storage batteries. The system will maximize the electrical energy from the generator with a battery capacity as a storage of electrical energy. There are two batteries that take turns with each other when Charging and Discharging. After reaching the maximum value on one battery, the system will switch to another battery. The advantage of this system is being able to regulate the process of charging and discharging energy on the battery. because if the battery goes through the Charging and Discharging process at the same time it will shorten the life of the battery. With the Automatic Switching method, it is hoped that in addition to extending the battery's life, it can also be able to optimize the storage capacity of electrical energy. 
Automatic Switching will be controlled by an electrical mechanical control system consisting of an Arduino microcontroller and a Relay. The Arduino microcontroller serves as the brain of this device and the Relay for its actuator. The combination of the two is then called Automatic Switching. Most of the renewable power generation systems in Indonesia still use manual controls that use analog circuits that only control simple processes and require operators to operate them. This is the reason for the creation of an automatic microcontroller-based Charging Management system to regulate battery charging in Hybrid power plants, and optimize battery capacity when Charging and Discharging

\section{LITERATURE REVIEW AND BASIC THEORY}

\section{A. Literature Review}

Literature review used as a reference in making this research, namely: in this study made by Michael Aditya Putra Pradana entitled "Automatic Battery Charging Control in Alternative Power Generation Systems" discusses the manufacture of battery charging controls with the smart switching method. In this tool uses a vertical shaft wind turbine and solar panel with Atmega 8051 controller with Relay actuators. Aims to control the charging and discharging process in storing electrical energy [1]. For research made by Muhammad Jubbari Fikri and Indra Yasri entitled "Aspects of Designing Hybrid Electric Systems" discusses the design of Hybrid electric management systems. This tool uses an ATmega 8535 microcontroller with a reference voltage and current sensors to control the process of moving the battery charging with a Relay [2]. After that the research made by Rangga Arianto, Arif Sulton Wijaya, Zainal Dudik, Mohammad Sirojuddin and Prima Arista with the title "Utilization of Hybrid Generating Technology in Chicken Farms in Sukonolo Village, Malang Regency". In this journal discusses the design of Hybrid Generators for Chicken Farms with lighting lamps. This tool uses a vertical shaft windmill and a solar panel with 1 battery with a Battery Control Regulator (BCR) as a Charging control. Thus, the utilization of 2 electricity sources can be optimized [3].

The conclusions obtained from previous studies the average microcontroller used using ATmega and its actuators using a relay.

\section{B. Basic Theory}

Solar Cell is a device that consists of solar cells that convert light into electricity. In general, Solar Cell is a semi-conductor that can absorb photons from sunlight and convert it into electricity [4].

Vertical axis wind turbine is one type of wind turbine that has a vertical axis with parallel blade blades with axes. This wind turbine rotates around the vertical axis. Vertical wind turbines have a smaller efficiency compared to horizontal axis wind turbines.

Solar Charger Controller is a device needed to monitor and control the charging of batteries connected with photovoltaic. The main function of this equipment is to limit the electric current entering the battery. Consists of a DC-DC converter that can increase or decrease the output voltage in accordance with the battery voltage. When the battery voltage increases, then Isolarcharge decreases and vice versa, when the battery decreases then Isolarcharge increases [5].

The battery management system or (BMS) is an electronic processing device to recharge the battery and also simultaneously monitor the state of the battery and to calculate secondary data that is on the battery. The main purpose of the BMS is to protect the battery from operating outside the safety zone (safety zone area). BMS must protect cells from all possibilities during discharging [6].

Combination control relay switch is a system to regulate input and output from 2 sources with the parameter capacity of the battery to be managed, There are 16 combinations with different variations.

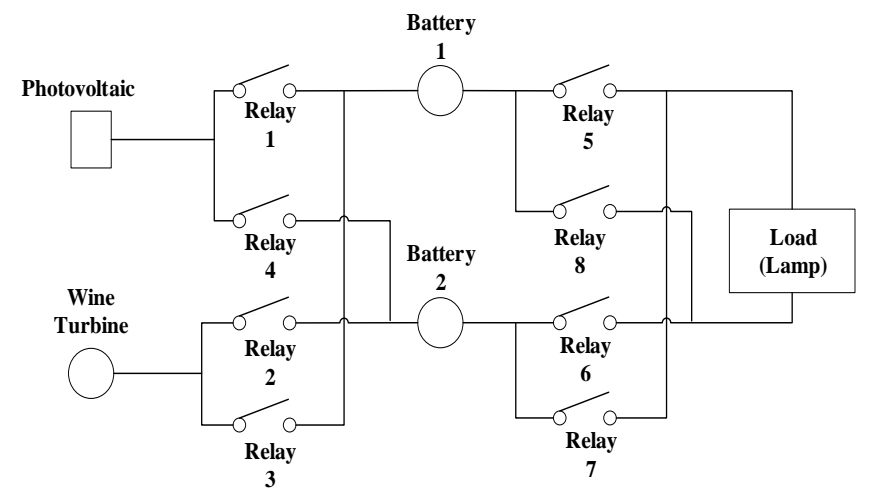

Fig. 1. The first combination

The first combination is used when the PV in off condition and the wind turbine is off. The first battery reads low voltage (12.4 volt or less) and second battery reads low voltage (12.4 volt or less) with the condition of the relay that is not connected.

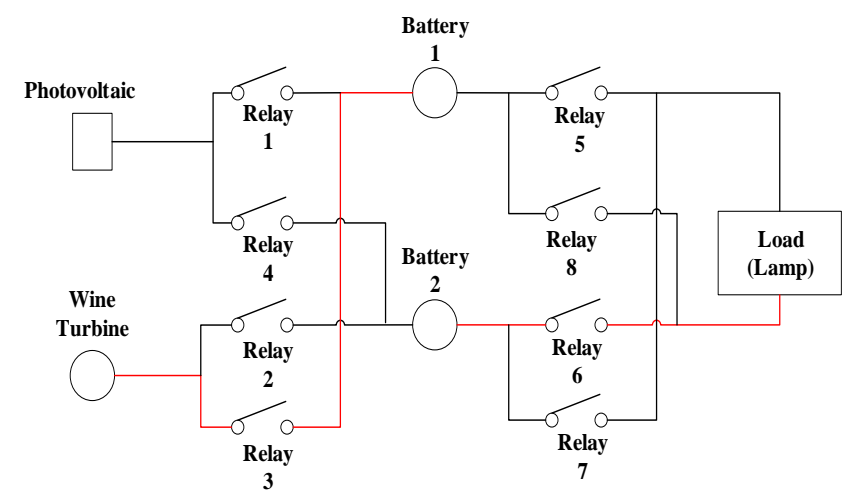

Fig. 2. Combination 2

The second combination, PV in off condition and wind turbine in working condition. the first battery is weak and the second battery is full, then the active relays are relays 3 and 6. 


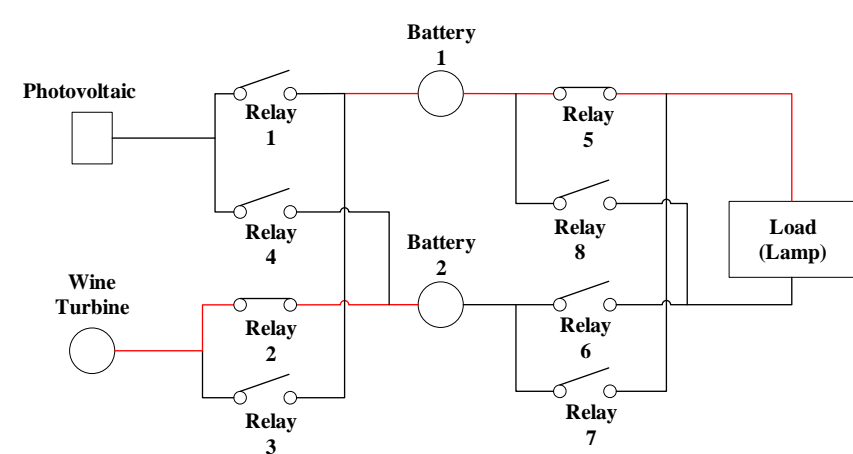

Fig. 3. Combination 3

The third combination, PV power is off and wind turbines working conditions. the first battery is in full condition and the second battery is in a weak condition, then the relays that will be active are 2 and 5 .

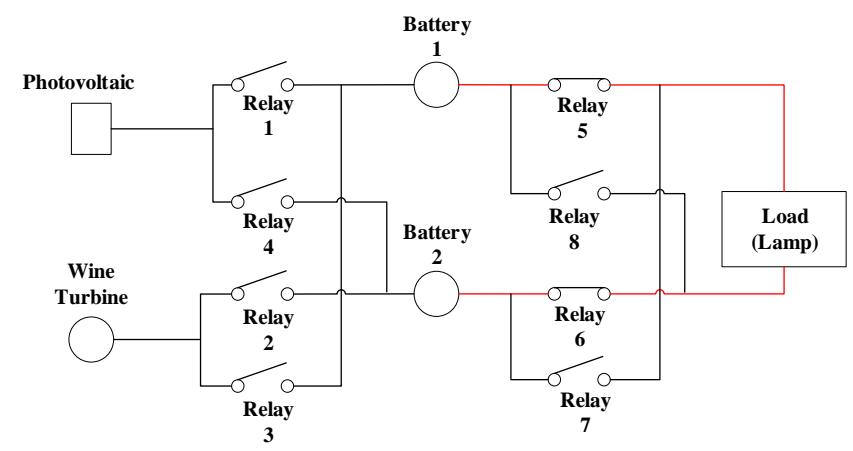

Fig. 4. Combination 4

The 4th combination is used when PV power and wind turbin is off conditions. the first battery the second batterery is in full condition, then the relays that will be active are 6 and 5 .

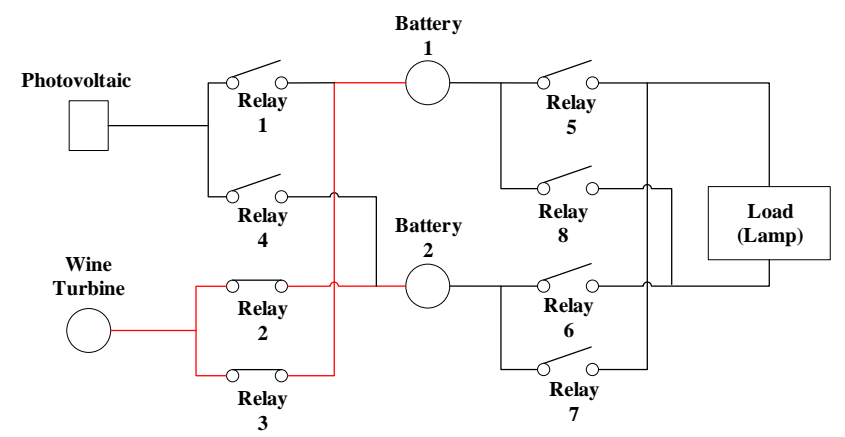

Fig. 5. Combination 5

The 5th combination is used when the PV is off condition and the wind turbine is on working condition with first battery and second battery is in a weak condition, then relays that will be activ are 2 and 3 .

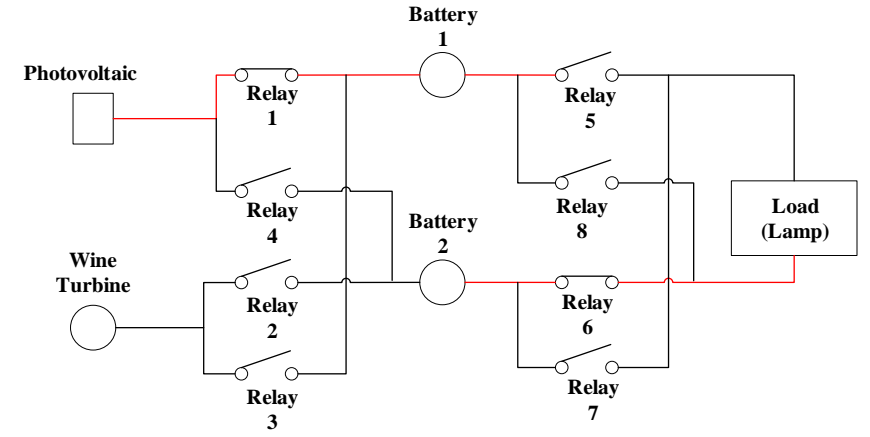

Fig. 6. Combination 6

The 6th combination is used when PV in working condition and wind turbine is not working condition, with the first battery in week condition and the second battery is in full condition, then relays that will be active are 1 and 6 .

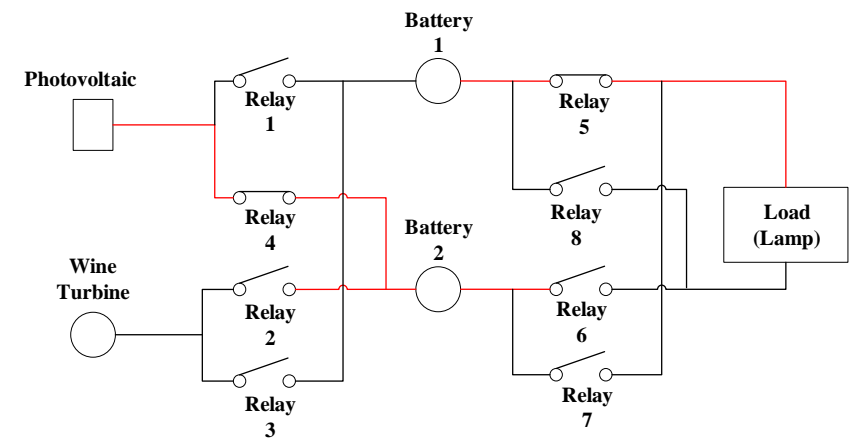

Fig. 7. Combination 7

The 7th combination is used when the in working condition and the wind turbine is not working condition, with the first battery in 1 full condition and the second battery in week condition, then relay that will be active are 4 and 5.

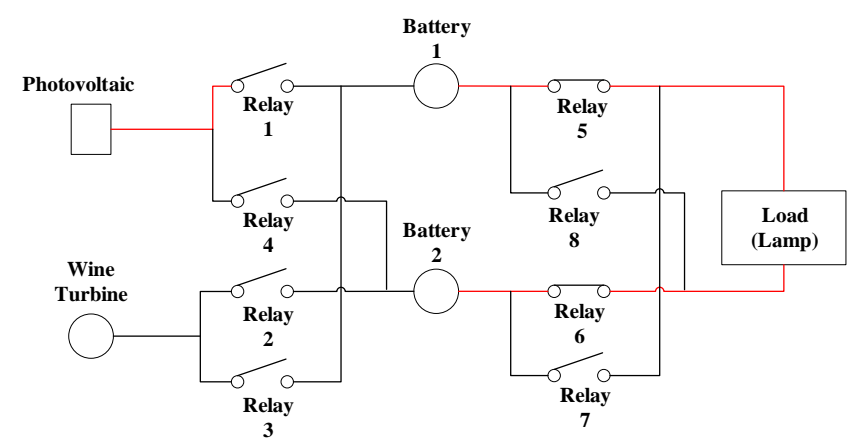

Fig. 8. Combination 8

The 8th combination is used when the PV power and wind turbine is off conditions, with the first battery and second battery is in 1 full conditio, then the relay that will be active are 5 and 6 . 


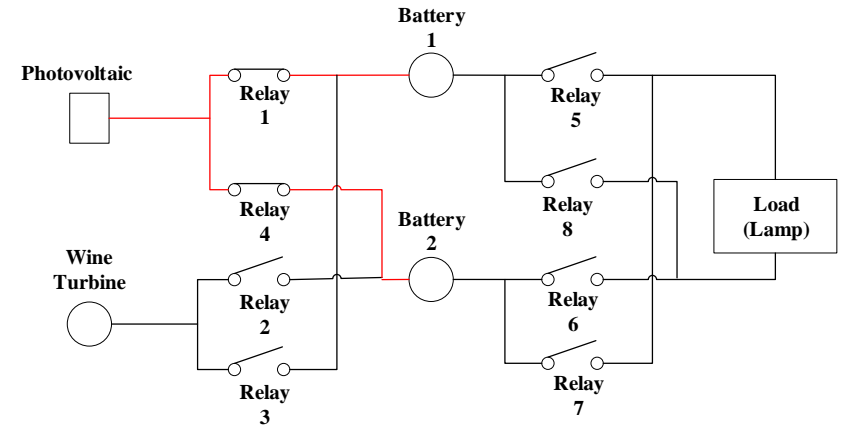

Fig. 9. Combination 9

The 9th combination is used when PV is on working condition and the wind turbine is off condition, with the first battery 1 and the second battey is in week condition, them the relay that will be active are 1 and 4 .

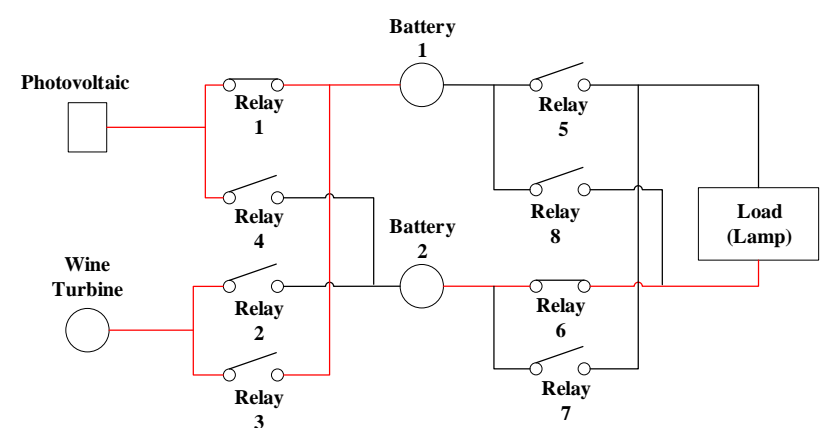

Fig. 10. Combination 10

The 10th combination is used when PV and wind turbine is in working condition, with the first battery is in week contion and the second battery in full, then relay that will be active are 1,3, 6 .

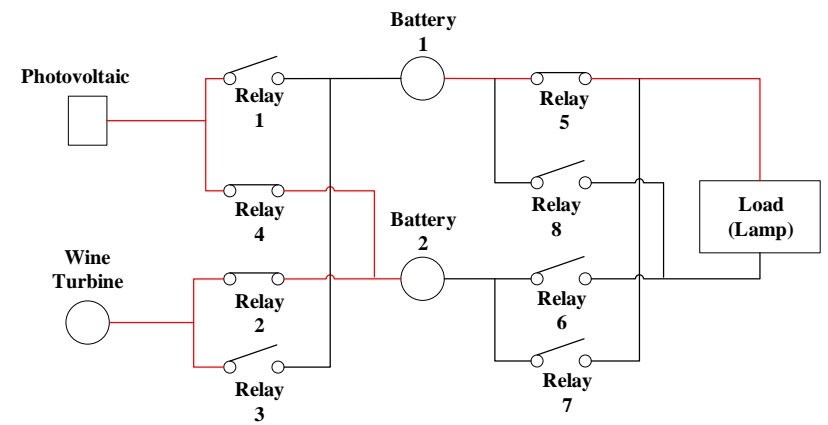

Fig. 11. Combination 11

The 11th combination is used when the PV and wind turbine is ini working condition, with the first battery is in full and the second battery is in week condition, then the relay that will be active are 2,4 and 5 .

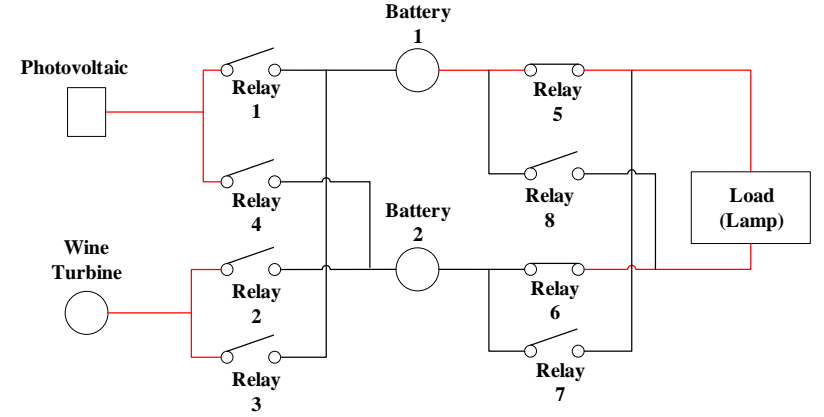

Fig. 12. Combination 12

The 12th combination is used when the PV and wind turbine is working condition, with the first battery and the second battery is in full condition, then that the relay will be active are 5 and 6 .

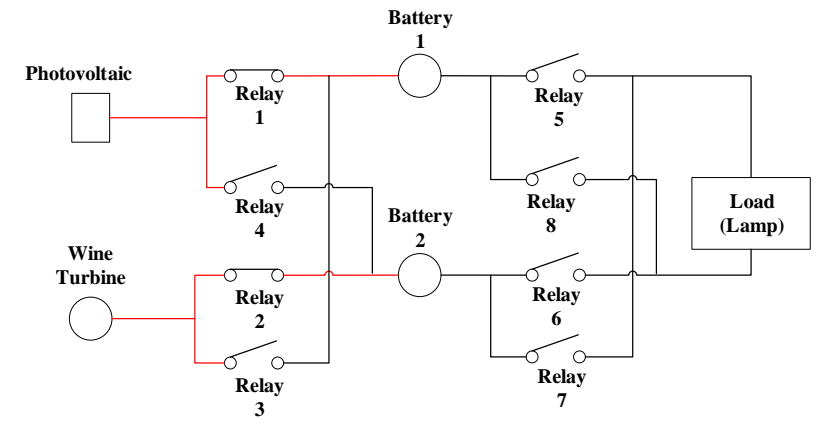

Fig. 13. Combination 13

The 13th combination is used when the PV and wind turbine is working condition, with the first battery and the second battery is in low voltage condition, then that the relay will be active are 1 and 2 .

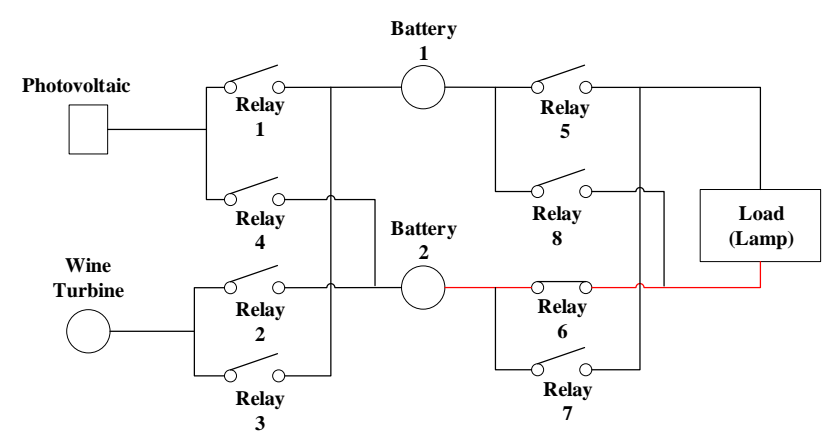

Fig. 14. Combination 14

The 14th combination is used when the PV and wind turbine is not working, with the first battery is in low voltage condition and the second battery is full vondition, then that the relay will be active are 6 . 


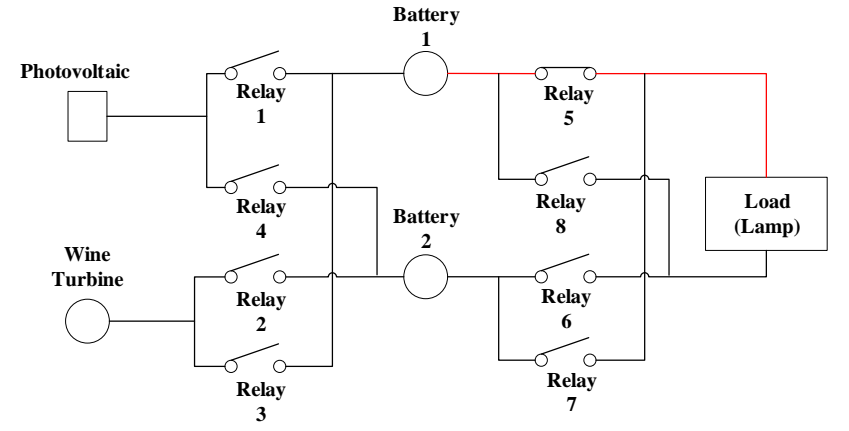

Fig. 15. Combination 15

The 15th combination is used when the PV and wind turbine is not working condition, with the first battery is in 1 full condition and the second battery is in weak condition, then that the relay will be active are 5 .

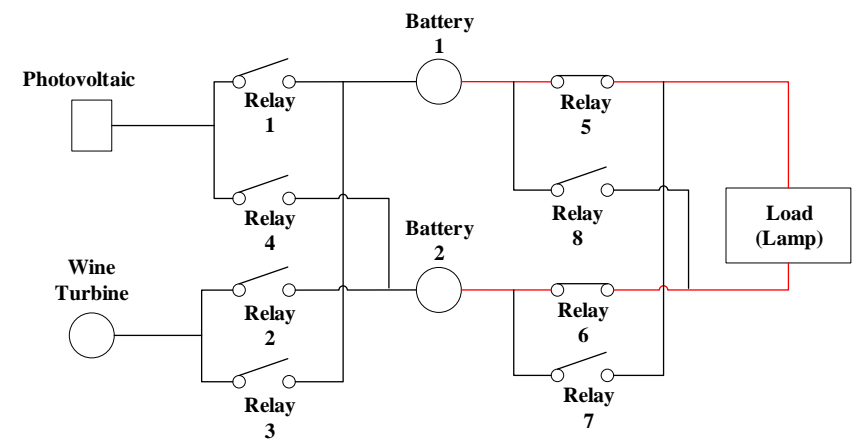

The 16th combination is used when the PV and wind turbine is not working, with the first battery and the second battery is full condition, then that the relay will be active are 5 and 6.

\section{RESEARCH METHODOLOGY}

In the section explaining block diagram systems, working tool flowcharts as well as management system combinations consisting of 16 combinations and explanation of each condition with variations in input voltage and battery capacity.

\section{A. Block System Diagram}

Figure 17 is a block diagram of the system of Hybrid Energy Charging Management system design with the Automatic Switching method based on the study of literature that has been studied. The working system of the Charging management tool is to charge the battery by monitoring sources that meet the Charging requirements and monitoring the capacity of batteries that meet the Charging requirements, as well as separating batteries that are full from the charging process.

Fig. 16. Combination 16

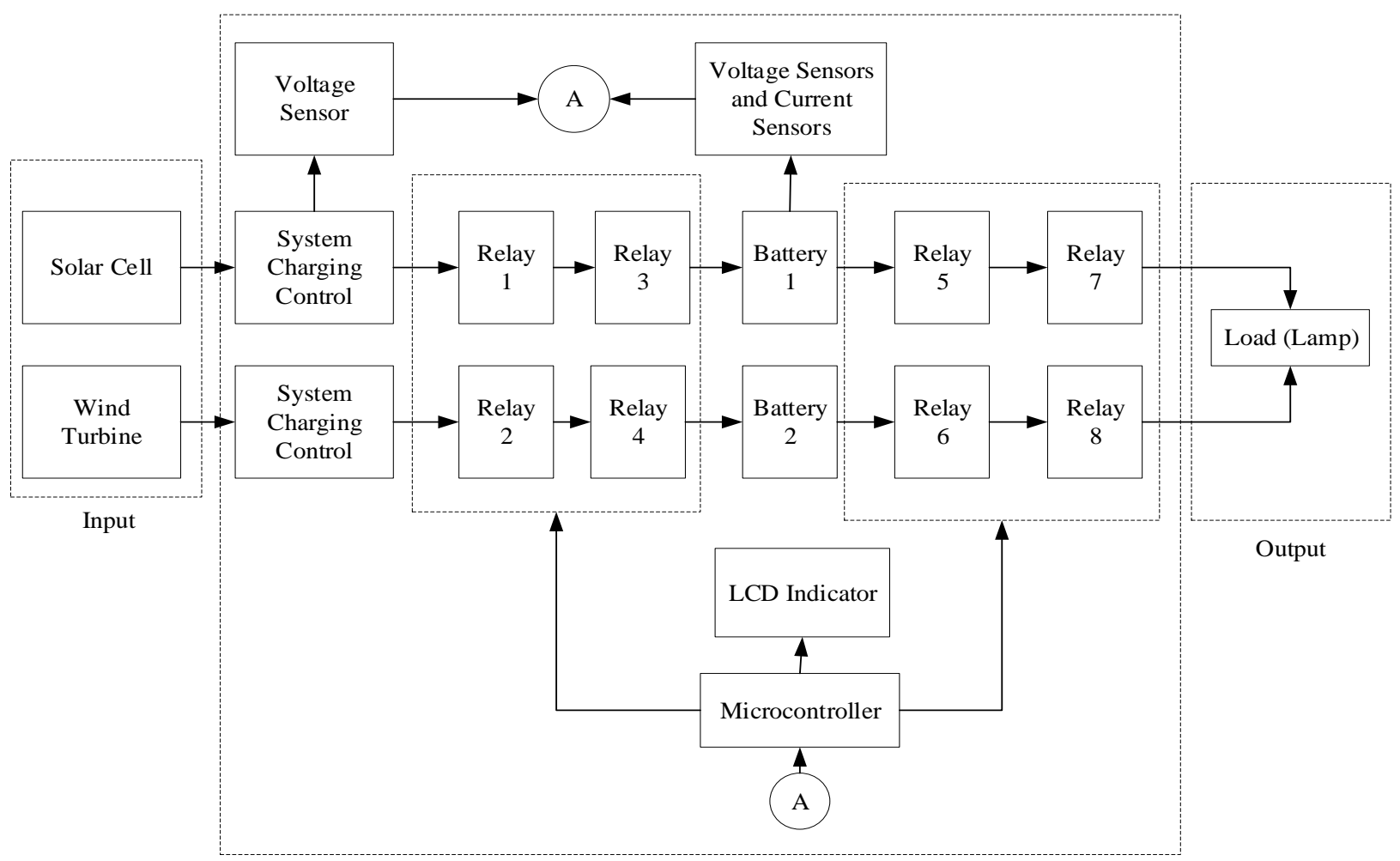

Process

Fig. 17. Block diagram of the system 


\section{B. Flowchart Sistem}

The system flowchart is close loop. From the whole system of adjustments between voltage and current sensors
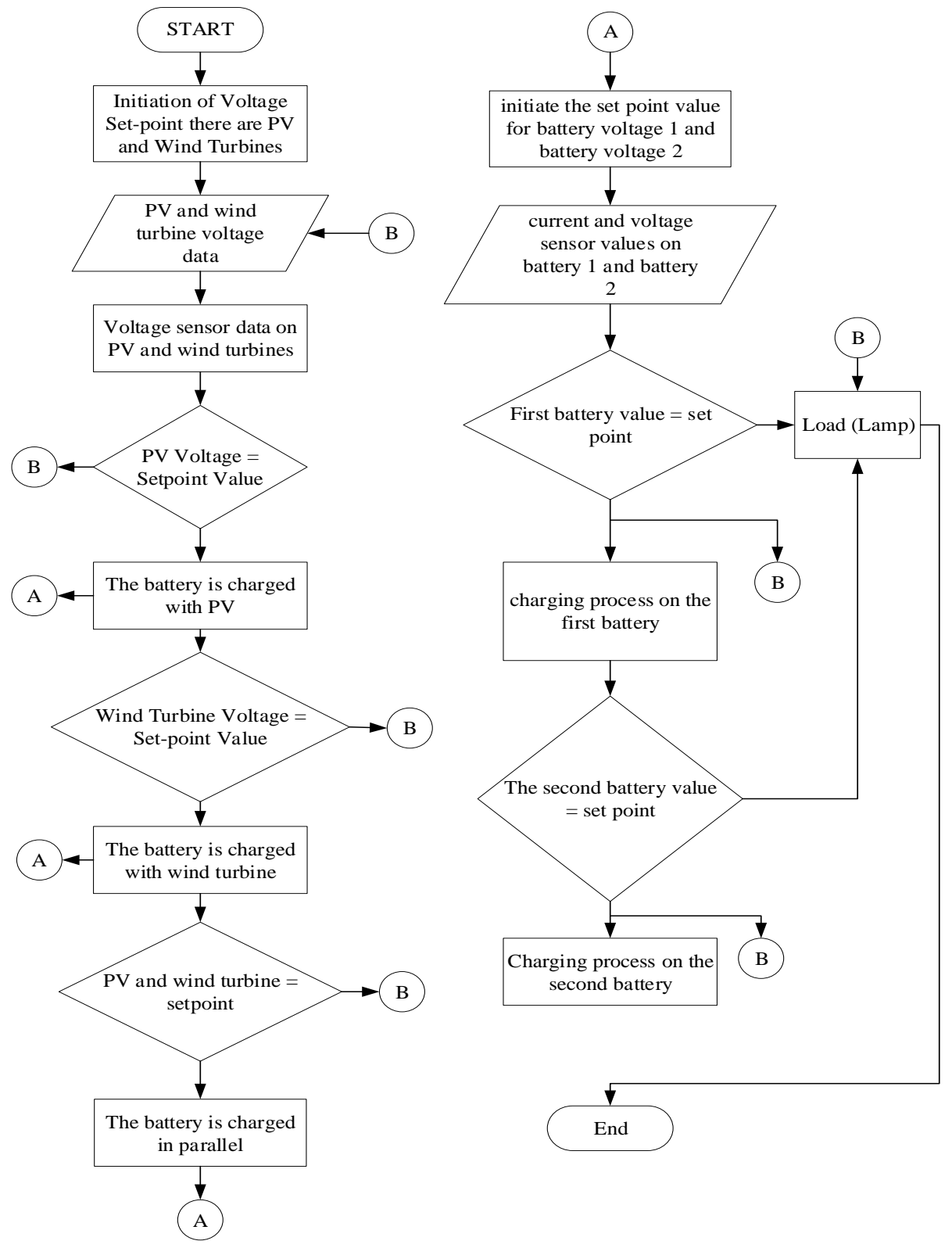

Fig. 18. Flowchart system

\section{Relay Mode}

The relay planning mode is a reference for coordinating the system, by coordinating the relay block 1 (relay 1,2,3 and 4) and the relay block 2 (relays 5, 6, 7 and 8) in order to carry out the battery charging process and battery usage. When the PV is in working condition and the wind turbine is not in working condition. Arduino microcontroller is used to activate the signal as a command to make the automatic switching system. There are 4 modes to simulate automatic switching, namely for charging the first battery using a combination mode $2,5,6,9,10,13$. Then for charging the second battery using a combination of $3,5,7$, $9,11,13$. From the side battery power usage or can be called a battery discharging system for battery power usage $6,8,10,12,14$ and 16. coordination combination 2 . is done to select the supply and battery sources used for the requirements of Charging and Discharging.

2 using a combination of $4,7,8,11,12,15$ and 16 . Whereas for battery power usage 2 that is using a combination of 4 ,

Charging mode for the first battery: Relay coordination for the first battery charging mode uses a combination of 2 , $5,6,9,10$, and 13. This mode is used when the PV output voltage is 13.7 volts up to 16 volts and the wind turbine output voltage is 0 volts to 13.6 volts. From this mode take example combination 2 where the active relay is relay 3 while for relays 1, 4, 2 are inactive. Can be seen from table 1 below that is the trigger planning table for relay 
TABLE I. TRIgGRE PlanNING For THE SECOND COMBINATION OF RELAYS

\begin{tabular}{|c|c|c|l|}
\hline No & Relay & Trigger & Information \\
\hline 1 & 1 & 0 & \multirow{2}{*}{ Battery 1 is } \\
Charging \\
\hline 3 & 2 & 0 & \\
\hline 4 & 3 & 1 & \\
\hline
\end{tabular}

Charging mode for the second battery: Relay coordination for the second battery charging mode uses a combination of $3,5,7,9,11,13$. In this mode is used when the PV voltage is 13.7 volts to 16 volts and the wind turbine output voltage is 0 volts to 13.6 volts. From this mode take example combination 3 where the position of the wind turbine is working while the PV condition is not working then the relay is active relay 2 while relays $1,4,3$ are not active. This condition will flow the current to the battery 2 . For more details can be seen in the table below.

TABLE II. TRIGgRE PlanNING FOR THE THIRD COMBINATION OF RELAYS

\begin{tabular}{|c|c|c|l|}
\hline No & Relay & Trigger & Information \\
\hline 1 & 1 & 0 & \multirow{3}{*}{$\begin{array}{l}\text { Battery 2 is } \\
\text { Charging }\end{array}$} \\
\hline 2 & 2 & 1 & \\
\hline 3 & 3 & 0 & \\
\hline 4 & 4 & 0 & \\
\hline
\end{tabular}

Discharging mode for the first battery: Relay coordination for the first battery discharging mode uses a combination of $4,7,8,11,12,15,16$. In this mode it is used when the battery 1 is fully charged with a voltage of about 13.7 volts to 14 volts. This discharging mode works when one of the batteries is in full condition. From this mode, take one example, combination 7 . In this seventh combination, battery 1 is in full condition, the relay will be active, relay 5 which will flow the battery from the battery to the load, the load here uses the lamp load. For more details can be seen in the table below.

TABLE III. TRIGGRE PlanNING FOR ThE Fourth COMBINATION OF RELAYS

\begin{tabular}{|c|c|c|l|}
\hline No & Relay & Trigger & Information \\
\hline 1 & 5 & 1 & \multirow{2}{*}{ Battery 1 is } \\
Discharging \\
\cline { 1 - 3 } 3 & 6 & 0 & \\
\hline 4 & 7 & 0 & \\
\hline
\end{tabular}

Discharging mode for battery 2: Relay coordination for the second battery discharging mode uses a combination of $4,6,8,10,12,14,16$. In this mode is used when the second battery is in full condition with a voltage of 13.7 volts to 14 volts. This discharging mode works when one of the batteries is in full condition. From this mode, take one example, the combination of 10 . In this tenth combination the second battery is in full condition, the relay will be active, relay 6 which will flow the battery from the battery to the load, the load here uses the lamp load. For more details can be seen in the table below.
TABLE IV. TRIgGRE Planning FOR The TENTH COMBINATION OF RELAYS

\begin{tabular}{|c|c|c|l|}
\hline No & Relay & Trigger & Information \\
\hline 1 & 5 & 1 & \multirow{2}{*}{ Battery 2 is } \\
Discharging \\
\hline 3 & 6 & 0 & \\
\hline 4 & 7 & 0 & \\
\hline
\end{tabular}

\section{TESTING AND ANALYSIS}

In this study, testing of several tools and their analysis is explained. With the test divided into several parts, including testing the voltage output from PV, testing the output voltage from the generator, testing the output of the voltage sensor, testing the current sensor output, testing the relay driver circuit, testing the input and output voltage \& current of the generator with a $140 \mathrm{Ohm}$ load resistor, testing hybrid energy system management tool Charging hybrid with automatic switching method, relay coordination testing.

\section{A. Testing Mode 1}

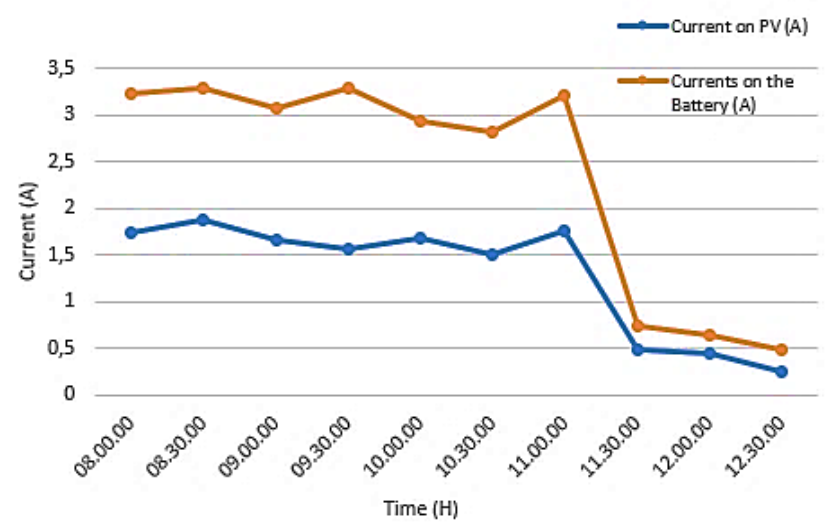

Fig. 19. Testing mode 1

In Figure 19, testing mode 1 is performed on a 12-volt 3.5 Ah battery with a PV voltage condition from 13.7 volts to 16 volts. Done by taking data every half hour from 8 to 12:30 hours stored on the SD card and measuring devices using a multimeter. In Figure 19, the time for charging the battery is 4.5 hours.

\section{B. Testing Mode 2}

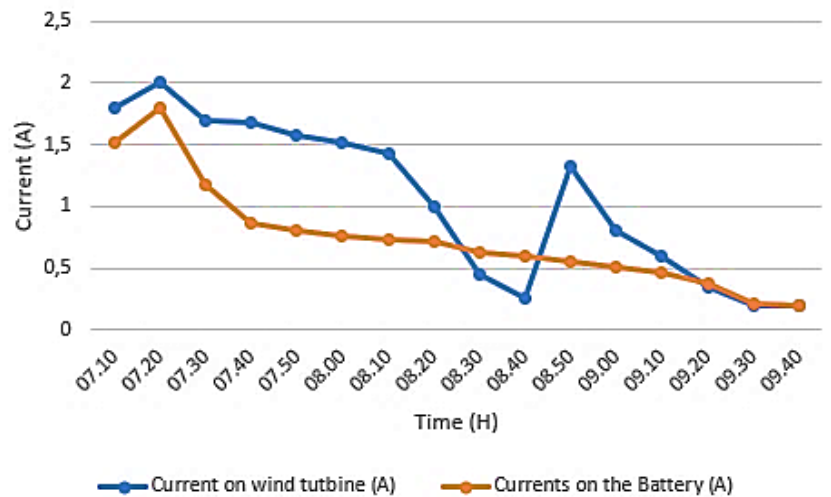

Fig. 20. Testing mode 2 
From Figure 20 a Charging test is performed on a 12volt 3.5 Ah battery with a generator voltage from 13.7 to 16 volts. Retrieval of data every 10 minutes from 8 to 9.40 and stored on SD cards and measuring devices using a multimeter. From Figure 20, the time for charging the battery is 2.4 hours.

\section{Testing Mode 3}

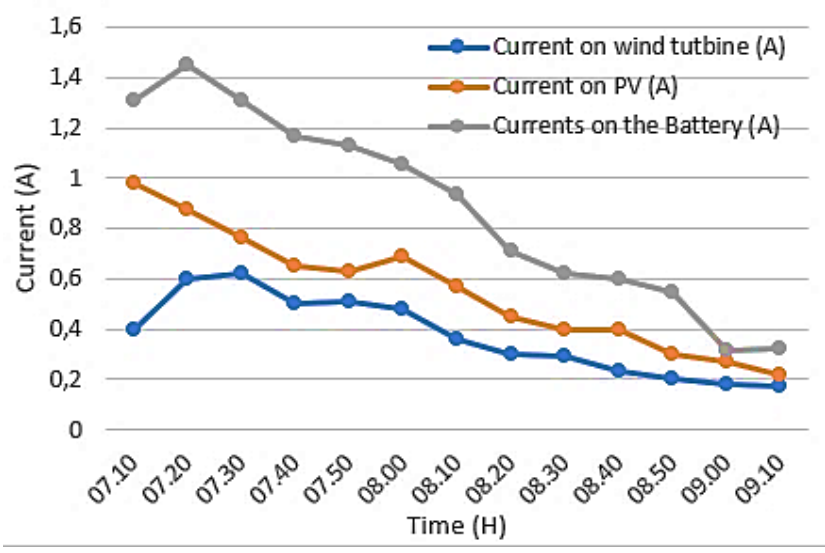

Fig. 21. Testing mode 3

From Figure 21 a Charging test is performed on a 12volt 3.5 Ah battery with a PV voltage condition of 13.7 volts up to 16 volts and a generator voltage of 13.7 volts up to 16 volts. Retrieval of data per 10 minutes from 7.10 to 9.10 hours is stored on the SD Card and measurement using a multimeter. From Figure 21, the time to Charging the battery is obtained for \pm 2.1 hours.

In modes 4,5 and 6 , no testing was performed because the relay coordination path was the same as the battery path 2. Mode 1 is the same as mode 4 , mode 2 is the same as mode 5 , and mode 3 is the same as mode 6 . From the testing of the three modes of mode 1 , mode 2 and mode 3 the data is obtained that charging using mode 3 is 30 minutes faster than mode 1 and 2.

When using a PV source fluctuating currents occur because the heat and temperature obtained during the experiment are unstable. When using a generator source (simulated with a 14.5-volt power supply source), the current obtained is stable compared to the PV source. When connected to 2 sources namely PV and the generator the current increases and there is heat in the power supply source due to reverse current due to a voltage difference of 1 volt. The settlement of this heat can be overcome by selecting the voltage sensor against the output voltage from the PV and the generator to be parallel with the condition that the voltage must be the same.

\section{CONCLUSION}

The conclusion obtained from this study is that the equipment can choose the source of the supply voltage and battery automatically based on the parameters of the Charging and Discharging requirements, with an average success of $90 \%$; using 2 sources of charging helps speed up battery charging 30 minutes faster than 1 source; for Mode 3 it has a faster charging capacity than mode 2 and mode 1 .

Suggestions for further research and development in this equipment is that additional batteries are needed for a more efficient system because the source can occur simultaneously when the battery is fully charged if there are only 2; each type of sensor must be tightly wrapped to obtain stable sensor data; very precise voltage control is needed when two DC sources are combined; There is an additional diode at the source and the direction to the battery for the current separator system because there is a backflow in the device that can just get into one of the battery or battery.

\section{REFERENCES}

[1] Zein, Ridwan, "The Process of Generating Wind Power Electricity in the West Group PLTH PandanSimo", Department of Electrical Engineering, Faculty of Engineering, Diponegoro University, Semarang, 2014.

[2] Purnamasari, Ratih., "Wind and Solar Electricity Supports the Beach", Master of Urban and Regional Planning at Gadjah Mada University, Yogyakarta, 2013.I. S. Jacobs and C. P. Bean, "Fine particles, thin films and exchange anisotropy," in Magnetism, vol. III, G. T. Rado and H. Suhl, Eds. New York: Academic, 1963, pp. 271-350.

[3] Aditya, M.P.P., "Automatic Battery Charging Control in Alternative Power Generation Systems", Sanata Dharma University, Yogyakarta, 2014.

[4] Muhammad Jubbari Fikri, Indra Yasri., "Hybrid Electric System Design Aspects", Riau University, Pekanbaru Riau, 2017.

[5] Arianto Rangga, Sulton Afif. W, Dudik Zainal, Sirojudin Muhammad, Arista Prima, "Utilization of Hybrid Power Generation Technology in Chicken Farms in Sukonolo Village, Malang Regency", Malang National Technology Institute, Malang, 2018

[6] Energy engineering and environmental conditioning laboratory. "Practicum Module for Converting and Converting Energy Engineering systems". ITS Physics Engineering, Surabaya, 2016. 